DOI: $10.1590 /$ permusi2015a3112

\title{
O violão na universidade brasileira: um diálogo com docentes através de um questionário
}

Fabio Scarduelli (UNICAMP/FAPESP, Campinas, SP)

fabioscarduelli@yahoo.com.br

Carlos Fernando Fiorini (UNICAMP, Campinas, SP)

fiorinic@unicamp.br

Resumo: O presente artigo apresenta a análise de um questionário aplicado aos professores de violão de universidades públicas brasileiras (estaduais e federais), em que são abordados os caminhos de técnica e repertório utilizados nestas instituições. A partir de uma participação ampla (com 95,4\% de participação das universidades que possuem curso de violão), foi possível elaborar um mapa do ensino do violão no Brasil, que poderá suscitar reflexões a respeito da pedagogia e do perfil dos profissionais formados nestes cursos.

Palavras-chave: pedagogia do violão clássico; bacharelado em violão no Brasil; bacharelado em música no Brasil.

The classical guitar in Brazilian universities:

a survey dialogue with teachers

\begin{abstract}
This article presents an analysis of a survey answered by classical guitar teachers of Brazilian public universities, as far as the technique and repertoire used at these institutions. Departing from a broad participation $(95.4 \%$ of the universities offering a degree in classical guitar), it was possible to draw a map of classical guitar teaching in Brazil. The results may raise questions about the pedagogy and the profile of the guitar alumni.
\end{abstract}

Keywords: classical guitar pedagogy; Bachelor's degree in classical guitar in Brazil; Bachelor's degree in Music in Brazil.

\section{Introdução}

Este artigo é parte de uma pesquisa de pós-doutorado (UNICAMP/FAPESP) cujo objetivo é a elaboração de um programa de curso que poderá ser oferecido ao Bacharelado em Violão da UNICAMP. Com o intuito de conhecermos uma variedade de cursos, a princípio brasileiros, nos propusemos um estudo dos programas de algumas reconhecidas instituições públicas de ensino. Entretanto, este caminho se mostrou um tanto árduo, já que tais programas, quando existem, podem estar, em grande parte, desatualizados, segundo depoimento dos próprios professores. Em geral, o que encontramos havia sido elaborado há bastante tempo e não representa necessariamente a realidade atual. Desta forma, verificamos que a maneira de conhecermos os cursos tais como de fato estão acontecendo seria conversarmos diretamente com os docentes. $E$, na busca por uma metodologia em que pudéssemos levantar informações em um maior alcance possível, concluímos que a forma mais eficiente seria a aplicação de um questionário. 
Para isso, seguindo propostas de BARROS e LEHFELD (1990), LAVILLE e DIONNE (1999) e PADUA (2000), procuramos uma otimização a fim de que levantássemos as informações mais relevantes em um número reduzido de questões (9 no total), procurando reduzir a possibilidade de diferentes interpretações, oferecer boa formatação visual, ordem e coerência de raciocínio, além da brevidade no tempo de preenchimento. Procuramos extrair informações relacionadas à existência e aplicação do programa de curso na instituição, formação do professor, seu direcionamento técnico e estilístico, a maneira como aborda técnica e repertório com os alunos e como distribui os conteúdos nos semestres / anos do curso.

Em nosso levantamento encontramos 22 instituições (excetuando-se aí a UNICAMP), das quais 21 tiveram participação, totalizando 95,4\%. Entretanto, ocorreu que em algumas universidades mais de um professor aceitou participar, o que achamos de grande valia, já que a forma de trabalho pode diferir de um docente para outro em uma mesma instituição. Desta forma, dos 48 professores de violão de ensino público encontrados, tivemos participação de 26 , representando assim $54,2 \%$ dos docentes do país.

\section{Análise das questões}

\subsection{Questão 1:}

Em sua instituição há um programa de curso para o bacharelado em violão?

a - ( ) Sim, existe e eu o sigo rigorosamente

b - ( ) Sim, existe mas eu faço adaptações

c - ( ) Sim, existe mas eu não o utilizo

d - ( ) Não há um programa de curso, trabalho de acordo com minha experiência e o perfil do aluno

e - ( ) Outro. Comente:

A QUESTÃO 1 se refere a um levantamento quanto a existência e utilização de programas de curso nas instituições brasileiras. Pode ser analisada do ponto de vista quantitativo e qualitativo. $\mathrm{O}$ aspecto quantitativo tem por finalidade verificar estatisticamente a presença e o uso de tais programas e, principalmente, a postura dos docentes perante eles. $O$ aspecto qualitativo visa analisar 0 depoimento dos docentes que optaram pela resposta aberta (item e), que dá espaço à reflexão.

Em uma primeira análise, verificamos que 19 universidades possuem um programa de curso definido, enquanto apenas 2 tomam como base a 
experiência do professor:

- Possuem programa de curso

Não possuem programa de curso

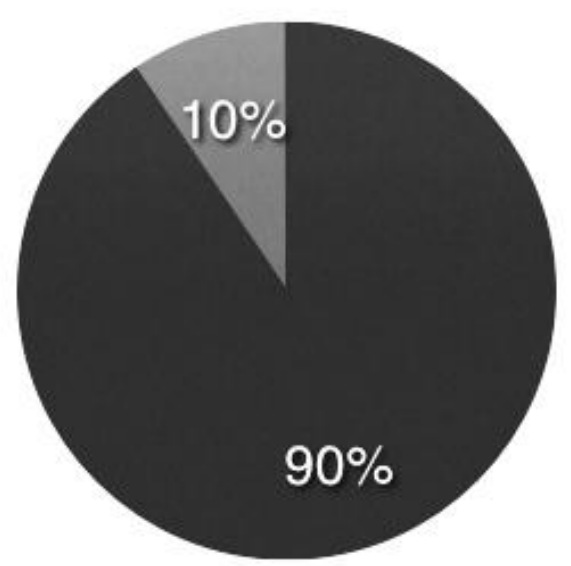

Ex.1 - Instituições que possuem um programa de curso para o Bacharelado em Violão.

Em relação à postura dos docentes, levando em conta apenas as universidades que possuem um programa, temos a seguinte situação:

- Segue com rigor - Faz adaptações • Não segue - Resposta aberta

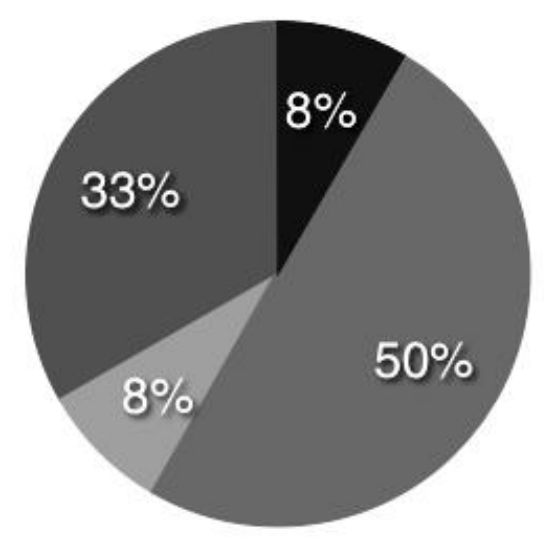

Ex.2 - Postura do docente em relação ao programa de curso.

A resposta mais recorrente (50\%) é a de que existe um programa mas que são feitas adaptações. De outro lado, apenas $8 \%$ afirmaram não seguir o programa existente, e também $8 \%$ declararam seguir rigorosamente o programa. Assim, observamos um baixo índice equilibrado dos extremos - os que usam rigorosamente e os que não usam - e um predomínio daqueles que adaptam às 
circunstâncias.

Entretanto, 33\% optaram pela resposta aberta, argumentando principalmente as adaptações feitas em relação ao programa pré-definido. Os pontos abaixo sintetizam tais argumentos:

- Há um programa que visa uma adaptação ao perfil individual de cada aluno.

- Etapas bem definidas, mas com repertório e técnica de acordo com o aluno.

- Programa em experiência, em fase de elaboração.

- Dá valor à escolha do aluno pelo repertório.

- Há um programa mas não é uma lista fechada, tomando como base três linhas: renascença-barroco, clássico-romântico, contemporâneo-brasileiro. Há uma lista aberta de obras, podendo ser acrescentadas novas obras.

- Há um programa, mas que tem se tornado inútil em função da variedade de perfis de alunos e, principalmente, diferentes maneiras de ensinar dos professores. Alguns fazem adaptações, outros não utilizam.

- É abrangente. Existem obras e períodos determinados, mas o restante é de livre escolha.

- Há a sugestão de que o aluno trabalhe peças de vários estilos, diferentes formas e conteúdos musicais, de menor e maior complexidade, e que no final apresente um recital. As aulas coletivas semanais de técnica possuem um programa definido, com técnica pura e ciclos de estudos progressivos. Há ainda música de câmera, repertório de violão, didática do violão, e as optativas camerata de violões e harmonia de violão.

- Ao longo de um ano o aluno deverá executar uma peça - ou grupo de peças de cada um dos períodos: renascença, barroco, clássico, romântico/espanhóis, contemporâneo, música brasileira. Assim o estudante deverá trabalhar 3 estilos por semestre. Há dois recitais obrigatórios durante o curso, um na metade e outro no final, e o aluno deve tocar um concerto para violão e orquestra com piano para uma banca.

Observando tais argumentos e o último gráfico exposto, verificamos que, em síntese, ocorre como tendência a flexibilização dos conteúdos, observando-se principalmente o perfil dos estudantes e, naturalmente, também do professor. Esta flexibilização pode estar presente em diversos aspectos do ensino, desde a técnica, em que o aluno estuda aquilo que de fato necessita (diferindo de antigas concepções em que prevaleciam cargas diárias de trabalho), até questões de estética, em que são respeitadas as escolhas de repertório pelos próprios alunos, ainda que seja privilegiada a abordagem da maior variedade possível de estilos. 


\subsection{Questão 2:}

Quem foi / foram seu (s) principal (ais) professor (es) de violão?

Segue abaixo a relação dos professores de violão mais citados pelos docentes, com a respectiva instituição e a cidade onde lecionam ou lecionavam ${ }^{1}$ :

\begin{tabular}{|c|c|}
\hline Professor & Instituição - Local \\
\hline Henrique Pinto & FAAM-FMU, EMM, Faculdade Cantareira e Particular \\
& $\begin{array}{c}\text { (São Paulo-SP) } \\
\text { ESP (São Paulo-SP) }\end{array}$ \\
\hline Edelton Gloeden & Particular (Montevideo - Uruguai) \\
\hline Tbel Carlevaro & UFRJ (Rio de Janeiro-RJ) \\
\hline Turíbio Santos & UNIRIO (Rio de Janeiro-RJ) \\
\hline Nícolas Barros & UFRJ (Rio de Janeiro-RJ) \\
\hline Léo Soares & Particular - São Paulo (SP) \\
\hline Fabio Zanon & Guildhall School of Music and Drama (Londres - \\
Inglaterra)
\end{tabular}

Os 13 professores citados acima somam 41 citações contra 37 dos demais (estes receberam apenas uma citação cada), representando assim 52,5\%. Com base nisso, ainda é possível perceber uma ênfase da formação dos atuais docentes nas capitais, principalmente no Rio de Janeiro e São Paulo. Percebemos também um número grande de professores estrangeiros citados, demonstrando um deslocamento frequente que ocorreu a ainda ocorre no Brasil, na busca por uma formação musical fora do país.

\subsection{Questão 3:}

Você se considera adepto de uma escola de técnica específica? Comente. 
Dos 26 docentes que participaram, 16 revelaram não pertencer a nenhuma escola de técnica específica, 8 disseram seguir a escola de Abel Carlevaro, 1 relevou ser adepto da escola de Tárrega, e 1 da escola de Segóvia. Desta forma temos:

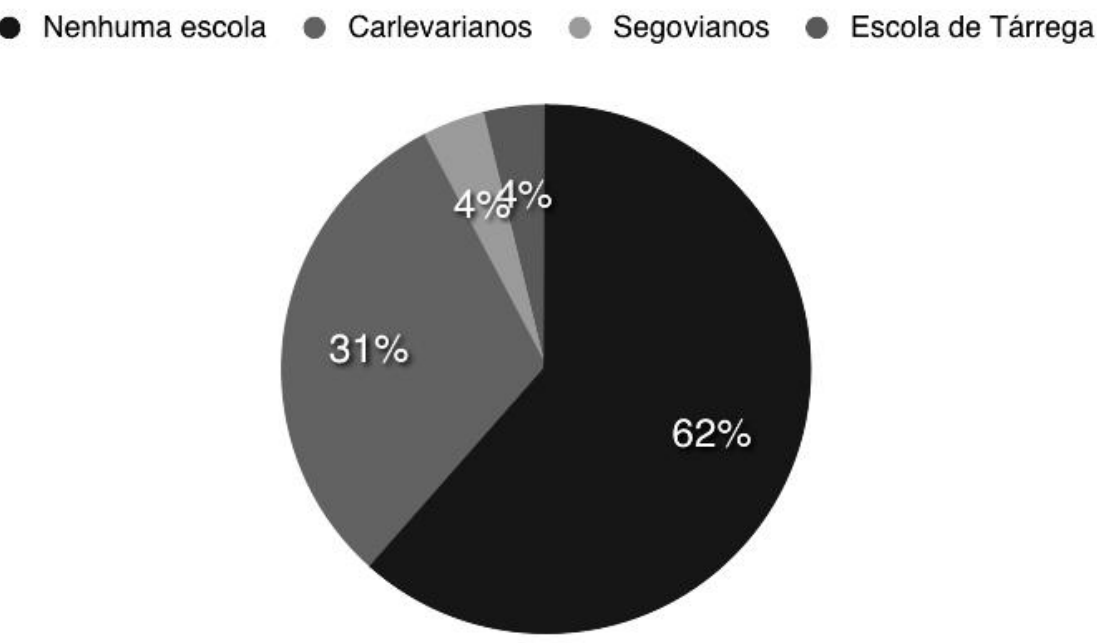

Ex.4 - Escolas de técnica de violão citadas nos questionários.

Verificamos então que a grande maioria respondeu não seguir nenhuma escola específica. Ainda assim, dentro desta resposta, 6 professores revelaram ter conhecimentos e aplicar, ainda que de forma não ortodoxa, os princípio de Abel Carlevaro. Desta forma, dentre as escolas citadas, destacamos os princípios de Carlevaro com 8 citações convictas e 6 mescladas a outras técnicas, totalizando 14 citações, para apenas 1 de Tárrega e 1 de Segóvia.

\subsection{Questão 4:}

Você trabalha técnica pura com os alunos? Como faz, quais materiais utiliza? Dos 26 docentes, 22 revelaram trabalhar técnica pura com seus alunos, resultando na seguinte proporção: 
- Aplicam a técnica pura

Não aplicam e são contrários ao estudo da técnica pura

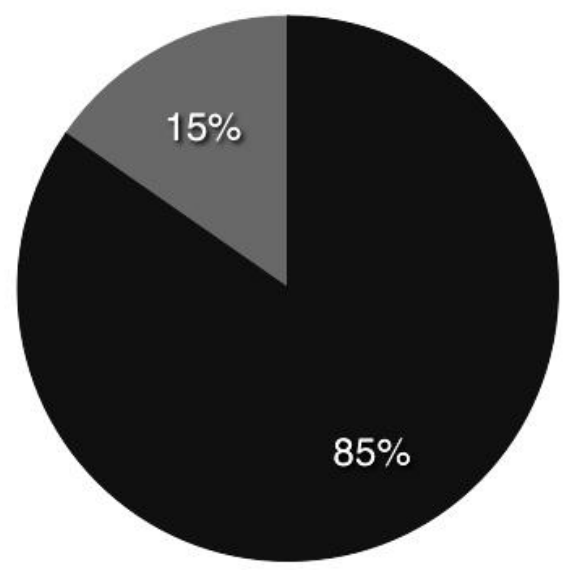

Ex.5 - Uso da técnica pura do violão nos cursos de graduação no Brasil.

Em relação aos materiais utilizados, segue abaixo uma lista de todos aqueles citados com o respectivo número de vezes em que aparecem:

\begin{tabular}{|c|c|c|}
\hline Material & Autor & $\mathbf{n}^{\mathbf{0}}$ vezes citado \\
\hline Série didática para guitarra (Cuatro Cadernos) & Abel Carlevaro & 16 \\
\hline Escuela Razonada de la Guitarra & Emilio Pujol & 6 \\
\hline Studio per la Chitarra Op.1 & Mauro Giuliani & 5 \\
\hline Pumping Nylon & Scott Tennant & 4 \\
\hline Escola Moderna do Violão & Isaías Sávio & 2 \\
\hline Técnica de mão direita & Henrique Pinto & 2 \\
\hline $\begin{array}{c}\text { Escuela de la Guitarra: exposición de la teoria } \\
\text { instrumental }\end{array}$ & Abel Carlevaro & 1 \\
\hline Exercícios de Independência e coordenação & Manuel Lopez Ramos & 1 \\
\hline Diatonic Major and Minor Scales & Andres Segovia & 1 \\
\hline Violão Prático & Eduardo Castañera & 1 \\
\hline Kitharologus & Ricardo Iznaola & 1 \\
\hline $\begin{array}{c}\text { The Natural Classical Guitar: the pinciples of } \\
\text { effortless playing }\end{array}$ & Lee Ryan & 1 \\
\hline La técnica de David Russel en 165 consejos & Antonio de Contreras & 1 \\
\hline $\begin{array}{c}\text { Técnica, mecanismo, aprendizaje: Una } \\
\text { investigación sobre el llegar a ser guitarrista }\end{array}$ & Eduardo Fernández & 1 \\
\hline Método para Guitarra & Dionísio Aguado & 1 \\
\hline Classic Guitar Technique (6 volumes) & Aaron Shearer & 1 \\
\hline
\end{tabular}

Ex.6 - Materiais didáticos mais usados pelos docentes brasileiros.

Destacamos nesta relação a concepção de técnica de Abel Carlevaro, com 16 citações de sua Série didática para guitarra e uma citação de seu livro Escuela 
de la Guitarra, em que teoriza seus pensamentos em relação aos mecanismos de execução. É importante ainda ressaltar que Carlevaro aparece entre os professores mais citados na QUESTÃO 2. Assim, podemos afirmar que o ensino do violão no Brasil tem forte influência de seu pensamento, em parte ligado às proximidades territoriais, mas certamente e, sobretudo, pela grandeza de seu pensamento, a tirar pela quantidade de grandes concertistas que direta ou indiretamente ajudou a formar.

Podemos também destacar dentre os materiais mais utilizados, além daqueles mais tradicionais como PUJOL (1961), GIULIANI (1812), SÁVIO (1985, s.d.) e HENRIQUE PINTO (s.d.), a presença de Pumping Nylon, de TENNANT (1995). Trata-se de um trabalho que tem sido largamente adotado por seu potencial sintético em relação aos principais mecanismos de execução, abordando-os de forma prática e direta.

Ainda em relação àqueles docentes que fazem uso da técnica pura, é interessante comentarmos alguns posicionamentos que são recorrentes ou que possuem especificidades. Em primeiro lugar, a postura predominante que percebemos é a combinação de diferentes métodos, com destaque para aqueles apresentados na tabela acima. Isto de certa forma corrobora com nossa análise da questão 3 do questionário, em que a maioria declara não pertencer a uma escola específica, aproveitando aquilo que cada uma pode oferecer de mais importante para a boa execução do repertório.

Logo em seguida, outra das respostas mais citadas diz trabalhar de acordo com as necessidades / dificuldades dos alunos. Os mecanismos não são tratados de forma ortodoxa, mas são resolvidos de acordo com a maneira como caminha o repertório e os problemas que este apresenta ao estudante.

Outras declarações revelam trabalhar de forma ortodoxa dentro de uma escola de técnica específica, principalmente a de Abel Carlevaro, citada por três docentes. Já outros professores criam seus próprio exercícios, baseados nos princípios de escalas, ligados e arpejos.

Uma outra postura verificada foi a de pensar os principais mecanismos de execução em variações próximas de como ocorrem no repertório. Assim, durante o curso são trabalhadas variações de toques, ornamentos, escalas, arpejos e ligados, a fim de que o aluno esteja preparado para estas ocorrências na medida em que o repertório venha exigir. Esta não é uma postura muito recorrente e demanda um conhecimento grande de detalhes da literatura do instrumento por parte do docente.

Podemos destacar também em algumas instituições a presença do trabalho de técnica em aulas coletivas. Tal prática tem o intuito de discutir os mecanismos básicos de execução de maneira focada, evitando tirar o tempo da aula individual para tal fim, aproveitando-a para o repertório. Um docente revelou que, em suas aulas, a carga de estudo de técnica é maior no início do curso, diminuindo gradativamente com o tempo e o aprendizado do aluno. Outro declara que procura resolver os fundamentos até metade do curso, utilizando 
uma disciplina específica para continuidade caso haja necessidade. E por fim, um docente declara que trabalha técnica desde que o aluno compreenda 0 porque deste tipo de estudo.

Dentre os que responderam não trabalhar técnica pura, realizam o aperfeiçoamento da execução de seus alunos através do próprio repertório, seja com técnica aplicada, extraindo trechos e criando pequenos exercícios mais próximos da necessidade, ou trabalhando diretamente no próprio trecho.

\subsection{Questões 5 e 6 :}

5 - Em seu trabalho como violonista/instrumentista há foco em algum repertório ou estilo específico? Qual (is)?

6 - Em seu trabalho com os alunos você procura enfatizar algum repertório ou estilo específico? Qual (is)?

As questões 5 e 6 são complementares, por isso são analisadas em conjunto. Possuem o intuito de verificar os direcionamentos estéticos nos cursos de graduação no país.

A resposta predominante em relação à postura didática dos docentes é, em $100 \%$ dos casos, o ecletismo. Todos afirmam recorrer à variedade estilística, passando por todos os períodos da história da música, a fim de que o aluno tenha uma formação sólida do ponto de vista da técnica, e ampla no que se refere à diversidade estética. $E$ isto independe da ênfase estilística que dá ao seu trabalho artístico como violonista. Podemos observar docentes que têm como foco a música brasileira (popular, nacionalista e de vanguarda), a música renascentista, barroca, clássica, latino-americana, contemporânea, repertório seresteiro e música espanhola. Assim, apesar das especificidades artísticas entre os docentes, todos afirmaram que recorrem à variedade em seu trabalho didático.

Destacamos em um dos questionários a afirmação de que a diversidade estilística é fundamental em um curso de bacharelado, e que o momento de especialização deve suceder o término do curso, com exceção dos alunos que entram na universidade com bases muito consistentes, fato que pouco ocorre em nossa realidade. $O$ docente conclui afirmando que o gosto musical do aluno deve ser levado em conta. Já outro professor considera um erro "que se crie cópias de seu modelo pessoal de repertório, técnica e interpretação, devendo sempre se respeitar aspectos da individualidade do aluno".

Uma declaração recorrente em alguns questionários se refere ao uso intenso do repertório clássico, de autores como Fernando Sor, Mauro Giuliani, Matteo Carcassi, dentre outros, como base para uma fundamentação técnica e fluência 
da execução. Um dos docentes considera este repertório como um relevante ponto de partida para a fluência, já que se caracteriza por uma aproximação ao universo dos alunos de sua instituição. Procura inserir gradativamente texturas polifônicas para, depois disso, recorrer à variedade. Esta postura é corroborada por um outro professor, que afirma que o aluno precisa trabalhar no primeiro ano do curso obras do século XIX e no segundo uma obra de Bach.

Nesta mesma direção, outra declaração afirma que compositores das escolas clássicas representam a escola de base. São autosuficientes no ensino do instrumento e servem de alavanca para o aprendizado de elementos musicais diversos. Há ainda em outro questionário a afirmação de que o aluno que não consegue tocar o repertório clássico com desenvoltura terá maior dificuldade em abordar repertórios de outros períodos. Revela que quando precisa rever fundamentos técnicos recorre a este período, que considera a base da pirâmide.

Com relação à música popular brasileira, há duas declarações em posicionamentos opostos. Uma delas possibilita uma abertura ao seu estudo. Já outra, revela não estimular o interesse. Podemos refletir que, em geral, os programas das instituições estão mais voltados ao repertório tradicional de concerto, com aberturas à música latino-americana.

Em relação a estéticas mais recentes, encontramos uma declaração de um docente que revela trabalhar algumas obras que se utilizam de técnica expandida ou de escrita diferenciada. Já outro professor acha relevante que o aluno estude obras que mesclem novos procedimentos tecnológicos.

Uma outra postura que nos chamou a atenção se refere ao trabalho de repertório partindo de obras de referência dos principais autores que escreveram para violão. Porém, em certo momento, indica que os alunos procurem um repertório diferenciado. Nesta mesma direção, outro docente declara que, após passar pelos pilares do repertório com o aluno, atravessando os períodos históricos, procura orientá-los a descobrir seu próprio foco de interesse.

Acreditamos que, de forma direta ou indireta, os docentes exercem influências sobre os alunos, pela dificuldade de se manter uma neutralidade durante os anos de orientação. Há exemplos raros que, de certa forma, contrariam esta afirmação, como é o caso de Isaías Sávio. Seus alunos se destacaram em diferentes meios e estilos, como Marco Pereira e Paulo Bellinati, em uma estética mais voltada à música popular, e Henrique Pinto, direcionado ao violão tradicional de concerto.

\subsection{Questão 7:}

Cite os compositores que você costuma trabalhar mais com os alunos. 
Abaixo estão listados apenas os 19 compositores mais citados pelos docentes (que receberam no mínimo 5 citações) de um total de 83. Pretende-se obter de forma aproximada, para uma análise conjunta com as questões 5 e 6 , os principais direcionamentos estilísticos dos cursos de graduação em violão no Brasil. Mesmo que os docentes tenham citado apenas alguns compositores mais trabalhados, a eleição destes pode ter um significado de representatividade dentro de sua hierarquia. Além disso, as tendências de repertório costumam mudar com o tempo, e a contribuição desta questão pretende mostrar um recorte atual.

\begin{tabular}{|l|c|}
\hline \multicolumn{1}{|c|}{ Compositor } & número de citações \\
\hline H.Villa-Lobos & 22 \\
\hline F.Sor & 21 \\
\hline J.S.Bach & 18 \\
\hline Leo Brouwer & 18 \\
\hline M.Giuliani & 17 \\
\hline F. Tárrega & 14 \\
\hline Manuel Ponce & 11 \\
\hline F. Moreno Torroba & 10 \\
\hline J.Rodrigo & 9 \\
\hline J.Turina & 8 \\
\hline L.Milan & 8 \\
\hline Mário Castelnuovo Tedesco & 7 \\
\hline L.Narvaez & 7 \\
\hline J.Dowland & 7 \\
\hline M.Carcassi & 6 \\
\hline A.Mudarra & 6 \\
\hline S.L.Weiss & 6 \\
\hline Radamés Gnattali & 5 \\
\hline A.Barrios & 5 \\
\hline
\end{tabular}

Ex.7 - Compositores mais citados pelos docentes no questionário.

Podemos verificar que dentre os mais citados não há uma tendência estética, mas uma escolha pelos ícones, o que corrobora com a análise da questão 6 , que valoriza o ecletismo e o conhecimento amplo da variedade estilística de todas as escolas. No topo da lista encontramos compositores renascentistas, barrocos, clássicos, românticos, neoclássicos e modernos, prevalecendo a variedade. Também estão presentes de forma maciça os compositores ligados à escola Segoviana, como Ponce, Torroba, Rodrigo, Turina e Tedesco. Isso demonstra de um lado o fascínio e a influência deixada por Segovia, mas também o valor artístico deste repertório, que até hoje permanece.

Entretanto, alguns compositores brasileiros de vulto e grande produção ainda aparecem pouco ou sequer são citados. A ausência de Marlos Nobre, Almeida 
Prado, Edino Krieger, Arthur Kampela, Theodoro Nogueira e Carlos Alberto Pinto Fonseca são notáveis. Paulo Porto Alegre, Jaime Zenamon, Isaías Sávio, Camargo Guarnieri, e Guerra-Peixe talvez precisem ser melhor conhecidos, em face de suas produções, já que aparecem com apenas uma única citação ${ }^{1}$. Em síntese, a música brasileira não está em primeiro plano em nossas escolas.

Pouco citada é também a obra de Abel Carlevaro, que parece ter uma participação mais efetiva no cenário brasileiro com seu método e concepção de técnica, apesar de ter uma obra relevante como compositor. Autores importantes da segunda metade do século XX também aparecem mais abaixo na tabela, demonstrando que estéticas mais vanguardistas acabam ficando de fora ou em segundo plano nos programas.

Ainda na segunda metade do século XX, mesmo aqueles compositores ligados a correntes neoclássicas, cuja obra é de grande relevância para o violão, também foram pouco citados, como os ingleses Wiliam Walton, Lenox Berkley e Benjamim Briten, com duas citações cada um. Curiosamente, compositores da segunda metade do século XIX também não estão na preferência, como Napolean Coste, Giulio Regondi e Johann Kaspar Mertz. Talvez isso se deva, tanto no caso da música do século XX como na música romântica, ao fato de que em geral este repertório apresente alguma exigência técnica que ultrapasse os propósitos pedagógicos e as possibilidades técnicas da realidade do estudante brasileiro.

Dos barrocos, o único não alaudista citado foi Robert de Visée, com apenas 1 citação. Não houve referências a Francesco Corbeta ou Gaspar Sanz, também guitarristas como de Visée.

Para finalizar, é interessante destacar uma declaração de um docente que revela que seu curso é baseado em uma tríplice orientação, a partir de Sor, Bach e Villa-Lobos, justamente os autores mais citados e que representam os três primeiros em nossa tabela. Isso demonstra, de certa forma, uma unidade no pensamento das instituições brasileiras.

\subsection{Questão 8:}

Como você distribui os conteúdos de técnica e repertório durante os anos de curso de um bacharelando?

Esta é uma das questões centrais do questionário para nossa pesquisa, por se aproximar de forma mais clara ao programa de curso da instituição. Embora esta temática tenha sido abordada indiretamente nas outras questões, este espaço complementa, sintetiza e corrobora as declarações a respeito da pedagogia no ensino superior. 
Aqui os docentes se posicionaram em relação à sua forma de trabalho, a maneira como conduzem o curso, abordam os conteúdos e acompanham o crescimento de cada aluno. A diversidade nas respostas, que reflete a individualidade de cada professor, nos faz priorizar uma análise qualitativa, através do estudo de cada depoimento. Entretanto, algumas respostas não entram em detalhes de conteúdo, versando mais em favor de uma relativização, na adequação ao perfil do aluno. Assim, nos ateremos aos depoimentos que refletem sobre conteúdos ou que possuem uma linha clara de pensamento para o curso.

Um dos professores consultados fala do primeiro semestre como um momento de estruturação, referindo-se à postura e atitudes das mãos esquerda e direita do aluno. Comenta o uso de arpejos, escalas e ligados como exercício para tal estruturação. Nos demais semestres são trabalhados outros conteúdos, como ornamentos e trêmulo, além do constante aprimoramento dos outros elementos.

Outro depoimento relata a necessidade de nivelamento dos alunos ingressantes. Assim, no primeiro ano há uma revisão de técnica. No segundo é preparado um repertório simples tecnicamente e variado em estilo. No primeiro semestre do terceiro ano são trabalhados estudos de Matteo Carcassi, Leo Brouwer e os Cadernos 3 e 4 de Abel Carlevaro. A partir daí, o foco estará no preparo do recital de formatura.

Em outra instituição o curso compreende 10 períodos, sendo que em cada um deles é necessária a realização de 2 estudos. Os quatro primeiros períodos são concentrados em uma revisão de técnica, utilizando-se também estudos de Matteo Carcassi, Fernando Sor, Mauro Giuliani e Heitor Villa-Lobos. Os conteúdos estilísticos, de repertório, são distribuídos de forma equilibrada entre os semestres.

Outro docente revela que em sua instituição o curso se inicia com estudos melódicos e pequenas peças clássicas visando a leitura, ainda sem o trabalho de técnica pura. Em uma segunda fase a técnica se torna presente em 20 ou $30 \%$ do tempo de aula. Depois disso, a técnica fica por conta do aluno, já que a atenção ao repertório toma cada vez mais conta do tempo.

Outro professor inicia com procedimentos técnicos mais ligados ao repertório clássico, já que considera este estilo um ponto de partida relevante a uma construção sólida das bases. Trabalha eixos de movimentação por corda comum e noções de dedo-guia para a condução do braço em diferentes posições no instrumento. Além disso, enfatiza limpeza da sonoridade, como apagadores de baixos e escalas com observação de timbre. A partir daí o aluno passa mais à abordagem de repertório em diferentes estilos e épocas, praticando questões pontuais de técnica de acordo com a necessidade da obra. $\mathrm{O}$ aluno trabalha 8 peças por semestre, sendo 3 de caráter didático e 5 de repertório. No decorrer do curso há ainda a integralização de obras completas, como suítes e sonatas, trabalhando-se dos movimentos mais simples aos mais complexos na medida em que os semestres avançam. 
Em outra instituição a exigência é que o aluno trabalhe no primeiro ano obras do século XIX. No segundo ano uma obra completa de Bach, e no último um concerto para violão e orquestra. $\mathrm{O}$ restante é livre, abrangendo todos os estilos e períodos.

Outra declaração relata que o professor dificilmente trabalha com dois alunos de forma igual. Entretanto considera o gênero estudo determinante para a condução do curso, por serem peças curtas e concentradas em determinadas técnicas. Tem preferência pelos clássicos como Sor, Giuliani e Coste, por conta da clareza da linguagem musical, ajudando a estruturar melhor a compreensão fraseológica e analítica dos discentes. Relata ainda que os estudos de Brouwer possuem o mesmo potencial, podendo substituir os clássicos.

Outro docente fala que no primeiro ano aplica essencialmente os estudos de Carcassi e Leo Brouwer, além de aprimorar algumas poucas obras escolhidas pelos alunos. No segundo ano trabalha os Prelúdios de Villa-Lobos, seus Estudos 3 e 4, além de uma obra clássico-romântica. Entre o segundo e terceiro ano é trabalhada uma obra polifônica renascentista, e do terceiro ano para frente uma suíte de Bach, geralmente um ou dois movimentos por semestre, até ser completada a obra. Ainda no terceiro ano o aluno estuda uma obra do repertório Segoviano ou uma obra consagrada da segunda metade do século $X X$. Já no quarto ano se volta a finalizar obras incompletas para a montagem do recital final.

Outro professor comenta que costuma pensar uma graduação contínua de conteúdos nos três primeiros anos, transferindo paulatinamente a iniciativa da escolha do repertório para o estudante. No quarto ano tende a deixar esta escolha bastante livre.

Em outra instituição, o professor fala dos dois primeiros semestres como um momento para se trabalhar os fundamentos técnicos, através de exercícios de escalas, ligados, saltos e arpejos. A partir do terceiro semestre inicia uma sequência de estudos progressivos de Sor (Op.60), Giuliani (Op.1), Carcassi (Op.25), Leo Brouwer, entre outros. Procura diversificar os trabalhos a fim de não sobrecarregar certos aspectos da técnica. Com relação ao repertório, trabalha com base na variação estilística. Comenta que certos estilos precisam de preparação, como por exemplo, tocar Robert de Visée, Brescianello ou Scarlatti antes de Bach. Da mesma forma Brouwer é usado como introdução ao repertório contemporâneo. Fala ainda do seu trabalho com melodias isoladas, observando fraseado, articulação e dinâmica em diferentes digitações, tanto de mão esquerda como de direita. Para isso, usa trechos de outros instrumentos ou do próprio violão, isolando a melodia do contexto polifônico. O objetivo é a formação do violonista enquanto músico completo.

Em outro depoimento o professor comenta que distribui os conteúdos de técnica de maneira mais ou menos livre, abordando essencialmente arpejos para mão direita e escalas para a esquerda, embora a separação ocorra apenas no âmbito teórico. Fala de um trabalho amplo com diversas escalas em todos os tons, 
através de material próprio, desenvolvido pelo professor. Com relação aos arpejos utiliza o Op.1 de Mauro Giuliani e os cadernos de técnica de Carlevaro. Comenta que o mais importante é que, escolhido o método, este seja realizado na íntegra. Entretanto, para qualquer método escolhido, nenhum é capaz de abordar a totalidade de situações, entrando aí o papel da técnica aplicada. Conclui falando que, em sua concepção, "técnica é autoconhecimento, de maneira que o aluno descubra quais caminhos podem fazer uma ideia musical funcionar melhor, e quais devem ser evitados".

Outro professor fala da importância do embasamento técnico nos primeiros semestres, até a metade do curso, com foco no repertório nos últimos semestres. Entretanto, tudo depende da condição em que o aluno ingressa, já que o teste específico não nivela.

Já outro docente trabalha técnica de base nos dois ou três primeiros semestres (ligados simples, arpejos, escalas, velocidade, extensores, distensões). Aplica combinações e técnicas mais complexas na medida em que o estudante evolui (trino em cordas duplas, trêmulo, rasgueados, ligados com dedos fixos).

Em outra instituição, um professor comenta que há aspectos comuns que devem ser abordados por todos, como a prática de escalas, ligados e arpejos, assim como algumas obras do repertório. Há ainda vários depoimentos que dizem primar pela periodização do repertório como guia para o desenvolvimento do curso.

Em certa instituição o professor tenta completar a base técnica até o final do violão IV. Se for necessário, o aluno pode continuar tais estudos matriculando-se na disciplina Fundamentos da Técnica. A partir deste ponto, não há mais obras obrigatórias e o aluno segue estudando a literatura, respeitando a variedade estilístico.

Alguns docentes comentam ainda a priorização da sonoridade no trabalho de técnica, ligado ao relaxamento, postura e lixamento das unhas. Já outros argumentam sua posição falando da impossibilidade de se pensar em uma distribuição mais ou menos fixa de conteúdos, devido a variedade de perfis e condições de ingresso dos estudantes, bem como por seus diversos interesses e perspectivas.

Para concluir, podemos observar de forma geral nos depoimentos a queixa de que os alunos ingressam no curso em certa defasagem com relação às expectativas dos professores e aos objetivos de um bacharelado. Desta forma, poucos conseguem uma profissionalização imediata como concertistas, e isso, muitas vezes acaba levando anos para que se consolide, até que atinjam uma certa maturidade. $E$ isso se deve em parte aos estudos musicais que antecedem a universidade, já que ocorrem de forma tardia ou deficiente. Assim, de acordo com grande parte dos depoimentos, os alunos entram despreparados tecnicamente e com pouca bagagem musical para obterem êxito ao se formarem. Desta maneira, boa parte do tempo do curso é destinado à resolução de bases. 
Podemos então sintetizar os caminhos da condução dos cursos revelados nos depoimentos:

- $\quad$ Fase de aprimoramento de bases

- Estudo da técnica pura e aplicada

- Estudos de Fernando Sor, Mauro Giuliani, Napolean Coste, Matteo Carcassi e Leo Brouwer

- Em geral, aplicação de estéticas clássicas, pela clareza musical e síntese instrumental idiomática

- $\quad$ Trabalho com peças curtas

- Fase de construção de um repertório visando o recital final

- Variação estilística como base da condução

- Integralização gradativa de obras no decorrer dos semestres

- Abordagem de obras polifônicas, harmônicas, passando por Sonatas, Fugas, Suítes e Concertos.

\subsection{Questão 9:}

Quanto a sua condução pedagógica:

a - ( ) O repertório aplicado aos alunos é pensado em função da técnica que está sendo trabalhada no momento;

b - ( ) A técnica é trabalhada em função de resolver um repertório ou estilo específico que está sendo aplicado;

c - ( ) Outra. Comente:

A questão tem o intuito de verificar, nas tendências pedagógicas atuais, o fio que conduz os cursos, se é a técnica ou o repertório. O resultado, em termos quantitativos, foi o seguinte: 
- alternativa a - repertório em função da técnica
alternativa b - técnica em função do repertório
alternativa c - resposta aberta

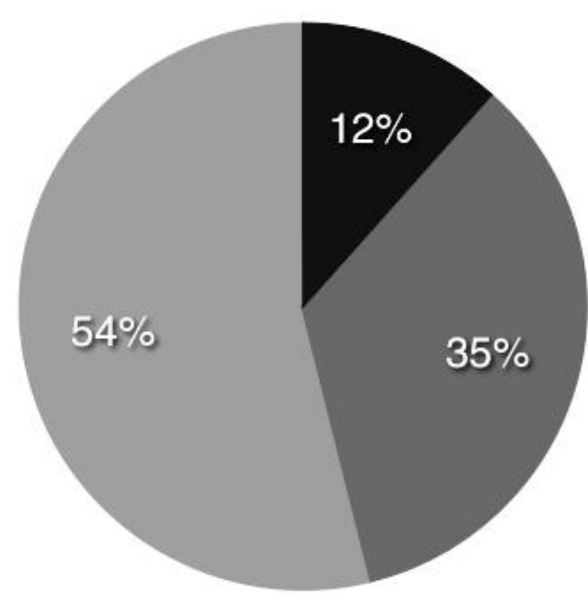

Ex.8 - Proporção de priorização de técnica e de repertório de acordo com o questionário.

Apenas 3 docentes marcaram a alternativa a, em que o repertório é pensado em função da técnica que está sendo trabalhada. Esta opção revela, de certa forma, a técnica como fio condutor do curso. Os diferentes estilos são trabalhados na medida em que se resolvem os mecanismos de execução.

Já 9 docentes optaram pela alternativa b. Neste caso, o repertório conduz 0 curso.

Entretanto, a maioria, 14 docentes marcaram a alternativa c, resposta aberta, que possibilita argumentação. Analisando os argumentos, podemos verificar uma tendência no sentido de que tanto a alternativa $\mathbf{a}$ como a $\mathbf{b}$ se aplicam. Um docente fala da complementariedade, que tanto se pode estudar técnica para um determinado repertório, como estudar repertório para uma determinada técnica. Em outra declaração o professor ressalta que o gênero estudo é aplicado visando uma resolução técnica, enquanto o repertório geral é escolhido em função de um aprimoramento estético. Outro docente, que marcou todas as alternativas, fala que "é difícil separar o assunto em a e b. A música é sempre o objetivo final, porém a alternativa a é necessária em função da necessidade de se construir, "quase do zero", alunos que prestam vestibular no interior do país".

Há ainda o caso de um curso que, dependendo do estágio, há foco em uma ou outra questão. A técnica é priorizada no $1^{\circ}$ e 3 ano, enquanto que no $2^{\circ}$ e e no $4^{\circ}$ o centro é o repertório. Esta alternativa parece interessante, pois possibilita tempo de reflexão e amadurecimento por parte dos alunos entre uma e outra atividade.

Em outro questionário, o docente revela que ambas as questões, técnica e repertório, não se relacionam necessariamente. $O$ aluno deve trabalhar os exercícios de mecanismos focados em escalas, ligados e arpejos, independente 
do repertório. O intuito é, segundo o professor, que se desenvolva um bom material orgânico para o fazer musical. Entretanto, a mesma declaração revela que o repertório deve ser escolhido para que o aluno conheça os vários estilos, dando-nos um indício de que parece ser este o fio condutor do curso.

Por fim, outra declaração revela que cada aluno representa um universo distinto, e que dificilmente se trabalha com dois alunos da mesma maneira. Leva em conta o estágio técnico, provável emprego de repertório no futuro, preferências estéticas e a carreira (se são do bacharelado ou de outros cursos). Entretanto, segundo o professor, é geralmente necessária a incorporação de obras curtas (estudos), visando uma estruturação mais adequada do domínio instrumental. Desta forma, a alternativa a é aplicada com frequência.

Assim, para concluir, verificamos que dentro da resposta aberta, que constitui a escolha da maioria, não há necessariamente uma priorização explícita. O que podemos verificar é que todos concordam que os alunos precisam ter um bom desempenho técnico durante o curso para que possam resolver o repertório de maneira eficiente. Para isso, além da técnica pura, muitos recorrem ao gênero estudo para tal fim, ou seja, escolhendo repertório com fins de aprimoramento instrumental. Já $47 \%$ dos docentes deixam claro qual é o seu fio condutor, sendo $35 \%$ guiados pelo repertório e desenvolvimento musical do aluno, contra apenas $12 \%$ daqueles que se orientam pela resolução dos mecanismos de execução.

\section{Considerações finais}

Quando analisamos a situação do ensino do violão nos cursos superiores não estamos apenas tomando referencias para a elaboração de um novo programa. Mas o que consideramos de maior importância nesta análise é a verificação dos caminhos tomados pelo violão na atualidade, a direção dos cursos na profissionalização dos instrumentistas. Verificamos que o caminho tradicional de ensino predomina, através de seu repertório com ênfase na tradição solista, com poucas referências à possibilidade de uma carreira camerística, por exemplo. Ainda que os cursos apresentem em sua estrutura curricular a disciplina de música de câmera, não há uma manifestação explícita dos docentes de violão no sentido de terem algum tipo de interferência neste possível campo de aprendizado de seus estudantes. Constatou-se também pouco espaço à contemporaneidade, verificado na lista de compositores citados. Também não se observou nas respostas ao questionário formas de incentivo a diálogos com compositores ou estudantes de composição. Isto pode ser um fato preocupante no que se refere a uma estagnação de repertório. É interessante que novos instrumentistas se interessem por tocar novas obras, e que novos compositores se interessem e tenham respaldo ao escreverem para violão. A atividade violonística pode ser enriquecida quando há uma interação com a produção artística local, saindo dos círculos fechados dos violonistas e penetrando em 
uma discussão mais ampla. Não estamos criticando de forma negativa a tradição histórica do violão, que em nossa concepção deve ser mantida. Nosso discurso defende a importância de termos um violão vivo, como instrumento ativo na contemporaneidade. O intuito do questionário não foi necessariamente discutir essas questões, e por isso não tem condições de dar um respaldo mais consistente sobre esse tema. Mas acreditamos que a ausência de referências a este assunto, especialmente pelo fato do questionário ter possibilitado discussões pelas questões abertas, mostra um pequeno sintoma que pode ser olhado com mais cuidado em nossas instituições. Desta forma, o breve mapa que apresentamos tem o intuito de incentivar a reflexão crítica sobre algumas tendências do ensino do violão no país, tomando como guia o entendimento de que a arte se faz a partir de caminhos criativos e que, desta forma, pressupõe-se que a criatividade deva estar no centro da formação, seja na escolha do repertório ou na forma de realiza-lo.

\section{Referências}

BARROS, Aidil de Jesus Paes; LEHFELD, Neide Aparecida de Souza. Projeto de Pesquisa: propostas metodológicas. Petrópolis: Vozes, 1990.

GIULIANI, Mauro. Studio per la Chitarra. Ed. Fac-simile. Vienna: Artaria,1812.

LAVILLE, Christian; DIONNE, Jean. A construção do saber: manual de metodologia da pesquisa em ciências humanas. Trad. Heloísa Monteiro e Francisco Sattineri. Porto Alegre: Artes Médicas Sul; Belo Horizonte: Ed.UFMG, 1999.

PÁDUA, Elisabete Matallo Marchesini de. Metodologia da Pesquisa: abordagem teórico- prática. 9a Ed. Campinas: Papirus, 2000.

PINTO, Henrique. Técnica de mão direita. São Paulo: Ricordi, s.d. PUJOL, Emílio. Metodo Razionale per Chitarra. Vol.1. Milão: Ricordi, 1961.

SÁVIO, Isaías. Escola Moderna do Violão: técnica do mecanismo. Vol. 1. São Paulo: Ricordi, 1985.

SÁVIO, Isaías. Escola Moderna do Violão: técnica do mecanismo. Vol. 2. São Paulo: Ricordi, s.d. TENANT, Scott. Pumping Nylon. USA: Alfred Publishing, 1995.

\section{Notas}

${ }^{1}$ A relação de professores citados foi extensa, e resolvemos publicar aqui apenas aqueles que aparecem com duas ou mais citações. A ordem que aparece na tabela é decrescente em relação ao número de citações.

${ }^{2}$ A tabela completa não foi publicada aqui por uma questão de espaço.

\section{Autores}


Fabio Scarduelli - Violonista, professor e pesquisador; Doutor e pós-doutor em Música pela Universidade Estadual de Campinas (UNICAMP). Graduou-se na Escola de Música e Belas Artes do Paraná e lecionou em instituições como a Universidade Federal do Rio Grande do Norte e a UNICAMP. Teve como professores de violão Mário da Silva, Luiz Cláudio Ferreira e Henrique Pinto. Apresentou-se em recitais em vários estados brasileiros, como solista e camerista. Seus alunos têm se destacado em concertos e concursos nacionais e internacionais. Participou como palestrante e concertista em eventos como o Simpósio Acadêmico de Violão da EMBAP, em Curitiba-PR, o IX Seminário Internacional de Violão Vital Medeiros, em Suzano - SP, o I Encontro de Educadores em Música de USP - Ribeirão Preto, dentre outros. Atualmente é professor adjunto da Escola de Música e Belas Artes do Paraná (UNESPAR) e professor colaborador do Programa de pós-graduação em Música da UNICAMP.

Carlos Fernando Fiorini - Doutor em Música (Regência) e Mestre em Artes (Música) pela UNICAMP, Carlos Fiorini graduou-se em Regência e Composição pela mesma instituição. Desde 1998 é docente da área de Regência do Departamento de Música da UNICAMP, onde atualmente é Coordenador de Graduação. Trabalhou como Regente Assistente das Orquestras Sinfônicas da Universidade Estadual de Londrina, de Sorocaba e de Bragança Paulista. Em 2000 e 2001 atuou como Regente e Diretor Musical do Festival "Aldo Baldin" de Florianópolis, e de montagens de óperas pela Cia. Ópera São Paulo. De 2005 a 2008 foi Regente Assistente e Titular da Orquestra Sinfônica Municipal de Campinas. Criou em 1996 a Camerata Anima Antiqua, grupo dedicado à música renascentista, do qual ainda é seu Diretor Artístico. Em 2009 criou no Instituto de Artes da UNICAMP um Centro Interno de Pesquisa dedicado à regência coral e orquestral denominado "Regência - Arte e Técnica", do qual fazem parte o Coro do Departamento de Música e a Camerata Anima Antiqua. 